\title{
Hydrogen Production Using "Direct-Starting" Biocathode Microbial Electrolysis Cell and the Analysis of Microbial Communities
}

\author{
Hong-Yan Dai ${ }^{1} \cdot$ Hui-Min Yang ${ }^{2} \cdot{\text { Xian } \text { Liu }^{3} \cdot \text { Xiu-Li Song }}^{3} \cdot$ Zhen-Hai Liang ${ }^{2}$ \\ Received: 7 April 2018/Revised: 21 June 2018/Published online: 1 August 2018 \\ (C) The Chinese Society for Metals and Springer-Verlag GmbH Germany, part of Springer Nature 2018
}

\begin{abstract}
In this study, a "direct-starting" procedure was used to activate a single-chamber biocathode microbial electrolysis cell (MEC) and the development of a biocathode was studied through output current curves and cyclic voltammograms. It only took $163 \mathrm{~h}$ for a successful start-up, and a current density of $14.75 \mathrm{~A} / \mathrm{m}^{2}$ was obtained. In the formal hydrogen-production stage, it was found that the biocathode MEC was comparable with the Pt/C cathode MEC in terms of current density and energy efficiency, and the hydrogen recovery, cathodic hydrogen recovery, and hydrogen production rate of the biocathode MEC were $71.22 \% \pm 8.98 \%, 79.42 \% \pm 5.94 \%$, and $0.428 \pm 0.054 \mathrm{~m}^{3} \mathrm{H}_{2} / \mathrm{m}^{3} \cdot$ days, respectively, which were slightly higher than those obtained with the Pt/C cathode MEC. Besides, under the effect of applied voltage, the microbial populations in the anodophilic biofilm of MEC (MECan) and the cathodophilic biofilm of MEC (MECca) were less diverse than those of the original aerobic activated sludge (AAS) and the anodophilic biofilm of MEC (MECan). Furthermore, the microbial community structures evidently differed between MECan/MECca and AAS/MFC.
\end{abstract}

Keywords "Direct-starting" procedure $\cdot$ Biocathode $\cdot$ Hydrogen production $\cdot$ Microbial community structures

\section{Introduction}

Due to its high energy density and zero emission properties, hydrogen is considered to be the most important energy carrier and fuel for the future [1,2]. Microbial electrolysis cells (MECs) developed from microbial fuel cells (MFCs) represent a novel technology for simultaneous hydrogen production and organic wastewater treatment $[3,4]$. Cathode, where hydrogen is produced, is an important part of an MEC. Nowadays, a variety of low-cost cathodes or cathode catalysts have been developed for practical utilization in MECs. In the past few years, various cathode materials such as stainless steel $[5,6]$, nickel and

Available online at http://link.springer.com/journal/40195

Hong-Yan Dai

daihongyan12@sina.com

1 Department of Municipal and Environmental Engineering, Taiyuan College, Taiyuan 030032, China

2 College of Chemistry and Chemical Engineering, Taiyuan University of Technology, Taiyuan 030024, China

3 Department of Chemistry, Taiyuan Normal University, Taiyuan 030031, China nickel alloys [7, 8], $\mathrm{MoS}_{2}$ [9], tungsten carbide [10], carbon/iron-based nanorod catalysts [11], and $\mathrm{Mg}(\mathrm{OH})_{2} /-$ graphene [12] were studied.

Biocathodes, using bacteria as catalysts for hydrogen evolution, have also been explored in previous studies. The first biocathode MEC for $\mathrm{H}_{2}$ production was developed by Rozendal et al. [13] through a three-phase start-up procedure: (1) enriching an acetate- and hydrogen-oxidizing bioanode after inoculation with mixed culture; (2) providing a microbial nutrient medium without carbon source to the bioanode and persistent hydrogen flushing; and (3) reversing the polarity of the electrodes. At a cathode potential of $-0.7 \mathrm{~V}$, the average current density of the biocathode reached $1.2 \mathrm{~A} / \mathrm{m}^{2}$, which is four times of that obtained by the control electrode. Jeremiasse et al. [14] studied complete biological MEC, in which both the oxidation and reduction reactions were catalyzed by microorganisms. The anode chamber was initially inoculated with the effluent from the bioanode of a previous MEC; after $600 \mathrm{~h}$, the cathode chamber was inoculated with the effluent from the biocathode of a previous setup. When $0.8 \mathrm{~V}$ was applied to the MEC, a current density of $3.3 \mathrm{~A} / \mathrm{m}^{2}$ was obtained and found to be comparable with that of a continuous membraneless MEC by using $5 \mathrm{~g} / \mathrm{m}^{2}$ 
load of platinum as the catalyst. Fu et al. [15] developed a thermophilic biocathode without reversing the polarity of the electrodes for the first time. First, the biocathode was developed in a single-chamber MEC, which was inoculated with the effluent of a thermophilic MFC operated for 3 months and then transferred into the cathode chamber of the two-chamber MEC, in which the anode was an abiotic fresh electrode. At a cathode potential of $-0.8 \mathrm{~V}$ versus standard hydrogen electrode (SHE), a current density of $1.28 \pm 0.15 \mathrm{~A} / \mathrm{m}^{2}$ and an $\mathrm{H}_{2}$ production rate of $376.5 \pm 73.42 \mathrm{mmol} / \mathrm{day} / \mathrm{m}^{2}$ were obtained, which were approximately 10 times as high as those of the non-inoculated electrode.

As biological catalysts for hydrogen evolution, biocathode microorganisms must contain hydrogenases in their cells to catalyze $\mathrm{H}_{2}$ production/consumption [16] and have the capability to overcome the thermodynamic limitation to form hydrogen with an externally applied voltage. Some researchers characterized the bacterial diversities of biocathodes $[17,18]$ and analyzed the hydrogenase genes present. Croese et al. [19] found that the sizes and carbon sources of MECs influenced the bacterial diversities of their biocathodes. Although the MECs were fed with acetate and bicarbonate separately, Firmicutes was the dominant group in small setups, whereas Proteobacteria and Bacteroidetes were identified as the prevalent groups in large MECs. When the large MECs received acetate but no sulfate, a nearly pure culture of Actinobacteria was found to be dominant. Furthermore, Croese et al. analyzed the hydrogenase genes present in the large MECs and found that most of the hydrogenase genes detected were coding for bidirectional Hox-type hydrogenases. Deutzmann et al. [20] studied the underlying molecular mechanisms of direct electron uptake in the microbial electrosynthesis processes and discovered that free, surface-associated redox enzymes, such as hydrogenases, are sufficient to mediate an apparent direct electron uptake. However, the original inocula, MFC bioanode, MEC bioanode, and MEC biocathode have not been compared in previous studies.

In this study, the formation of the biocathode was analyzed through cyclic voltammograms (CVs) and outputcurrent curves. Scanning electron microscopy (SEM) was used to characterize the morphology of the microorganisms. The bacterial diversities were determined by $16 \mathrm{~S}$ amplicon sequencing. The performance of the biocathode MEC was evaluated in terms of current density, coulomb efficiency and hydrogen production and compared with that of an MEC using platinized carbon paper $(\mathrm{Pt} / \mathrm{C}$, $0.5 \mathrm{mg} / \mathrm{cm}^{2}$ ) as the cathode.

\section{Materials and Methods}

\subsection{MEC Construction}

The previously described single-chamber MECs were used in this study [12]. The carbon felt $(2 \mathrm{~cm} \times 4 \mathrm{~cm} \times 1 \mathrm{~cm}$, BJSY-10, Sanye Carbon Co., Ltd., Beijing, China) and carbon paper $(2 \mathrm{~cm} \times 4 \mathrm{~cm}, \mathrm{HCP} 030 \mathrm{~N}$, Hesen Electric Co., Ltd. Shanghai, China) were, respectively, used as anode and cathode. The spacing of anode and cathode was $1.5 \mathrm{~cm}$. The nutrient solution contained $\mathrm{NaAc} \cdot 3 \mathrm{H}_{2} \mathrm{O}$ $1.36 \mathrm{~g} / \mathrm{L}$ (the organic substrate), $\mathrm{KCl} 0.13 \mathrm{~g} / \mathrm{L}, \mathrm{NH}_{4} \mathrm{Cl}$ $0.31 \mathrm{~g} / \mathrm{L}$, trace mineral element solution $20 \mathrm{~mL}$ [21], and $100 \mathrm{mmol} / \mathrm{L}$ phosphate buffer solution $(\mathrm{pH}=7.0$ ). Prior to inoculation, the nutrient solution was sparged with $\mathrm{N}_{2}$. The gas produced by the MEC was collected in tubes with a total range of $100 \mathrm{~mL}$ using water displacement. A copper wire was used to connect the electrodes and power source to the circuit.

\subsection{MEC Operation}

An inoculated anode from an acetate-fed MFC was installed into the MEC. Unmodified carbon paper $(2 \mathrm{~cm} \times 4 \mathrm{~cm})$ was used as the cathode. Before testing, the carbon paper was submerged, respectively, in $\mathrm{HCl}(1 \mathrm{M})$ and $\mathrm{NaOH}(1 \mathrm{M})$ for $24 \mathrm{~h}$, and then washed with deionized water for several times. Twenty milliliters of aerobic sludge from the aeration tank of Yangjiapu's municipal wastewater treatment and $50 \mathrm{~mL}$ of nutrient solution were injected into the MEC. A fixed voltage of $0.7 \mathrm{~V}$ was applied to the MEC by a power source (HB 17,301 SL; Hossoni, Inc., China).

The MEC was operated in fed-batch mode. When the current of the MEC was lower than $0.5 \mathrm{~mA}$, the supernatant was replaced with $50 \mathrm{~mL}$ of fresh nutrient solution, and the electrodes were exposed to air for $20-30 \mathrm{~min}$ to inhibit the growth of methanogens [22]. All batch tests were performed at a room temperature of $20{ }^{\circ} \mathrm{C}$ and run in duplicate.

\subsection{Measurement and Analysis}

The growth of the biocathode was analyzed through cyclic voltammograms and output current curves. An electrochemical workstation (Princeton Applied Research, USA) with a three-electrode system, including a working electrode (biocathode), a counter electrode (anode), and a saturated calomel electrode (SCE), was used for cyclic voltammograms. The morphology of microorganisms was characterized by SEM (JSM-7001F, JEOL, Japan). Before SEM measurements, the biocathode samples were prepared 
according to the steps of Ref. [23]: (1) sampling, small pieces of carbon paper were removed from biocathodes by scissors; (2) fixation and washing, the samples were fixed with $2.5 \%$ glutaraldehyde for $2 \mathrm{~h}$ and washed with $0.1 \mathrm{~mol} /$ L phosphate buffer solution; (3) dehydration, ethanol solutions with $30 \%, 50 \%, 70 \%, 80 \%, 90 \%, 100 \%$ concentration were used each for $15 \mathrm{~min}$ to gradually dehydrate the fixed specimens; (4) $\mathrm{CO}_{2}$ critical point drying and sputtering with gold. The bacterial diversities were determined by $16 \mathrm{~S}$ amplicon sequencing technology. Before desoxyribonucleic acid (DNA) extraction, the approaches to prepare the three kinds of samples were as follows. The carbon paper was crushed for DNA extraction, after gently rinsing the biocathode with deionized water. The top, middle and bottom sections of anode carbon felt were cut, fragmented and mixed, and then rinsed with deionized water so that the residual sludge could be removed. Four milliliters of original aerobic activated sludge was centrifuged at $10,000 \mathrm{rpm}$ for $3 \mathrm{~min}$ to remove supernatant, and about $0.25 \mathrm{~g}$ pellet was used for DNA extraction. Total genomic DNA was extracted with E.Z.N.A. Soil DNA Kit referring to the manufacturer's instructions. The quality and quantity of extracted DNA were examined with Qubit 2.0 DNA detection kit. A $464 \mathrm{bp}$ fragment of the $16 \mathrm{~S}$ rRNA gene was amplified with the V3-V4 universal primers $341 \mathrm{~F}$ ( $5^{\prime}$-CCTACGGGNGGCWGCAG-3') and 805R (5'-GACTACHVGGGTATCTAATCC- $\left.3^{\prime}\right)$ with Illumina adapters at the $5^{\prime}$ ends for 20 cycles. A second round of 5 cycles of PCR was used to add index sequences and the Illumina MiSeq adapters. An Illumina MiSeq platform was used to carry out $16 \mathrm{~S}$ amplicon sequencing according to standard protocols [21]. To analyze bacterial diversity and microbial community structure of the four samples, the sequences were clustered into operational taxonomic units (OTUs) with the MOTHUR program by setting a 0.03 distance limit (equivalent to $97 \%$ similarity). The performance of the biocathodes was evaluated in terms of current density, coulomb efficiency and hydrogen production as previously described [4].

\section{Results and Discussion}

\subsection{Development of Biocathode}

The single-chamber MEC with an inoculated anode and unmodified carbon paper cathode was started up by applying a fixed voltage of $0.7 \mathrm{~V}$. After turning on the power supply, the current density of the MEC increased, reached a peak value, and then decreased because of sodium acetate depletion (Fig. 1a). In the first five operation cycles, the maximum current density of the MEC increased, and the time span of each cycle was shortened.
In the initial operation period, few microbes adhered to the unmodified carbon paper, and the catalytic activity for hydrogen evolution was minimal. As a result, in the first cycle, the peak current density was only $2.708 \mathrm{~A} / \mathrm{m}^{2}$ (projected cathode area), and the running time was $31 \mathrm{~h}$. As the running time increased, electroactive microbes gradually adapted to the environment, and some microbes with catalytic activity for hydrogen evolution attached to the unmodified carbon paper, which initiated the catalytic activity for hydrogen evolution of the carbon paper [14]. In the second cycle, the peak current density was $4 \mathrm{~A} / \mathrm{m}^{2}$, which was slightly higher than that in the first cycle. The running time was shortened to $30 \mathrm{~h}$. The appearance of several tiny bubbles on the carbon paper indicated the generation of hydrogen. The peak current densities in the third, fourth and fifth cycles were 8.025, 12.525 and $14.75 \mathrm{~A} / \mathrm{m}^{2}$, respectively. These densities are remarkably higher than those in the previous cycles. The running times were further shortened to 28,26 , and $24 \mathrm{~h}$ in these three cycles. The bubbles on the carbon paper increased and constantly overflowed from the water surface. This phenomenon indicated the promotion of the catalytic activity of the biocathode. In the sixth cycle, the peak current density was $14.625 \mathrm{~A} / \mathrm{m}^{2}$, and the running time was $24 \mathrm{~h}$, both of which were similar to those in the fifth cycle. Thus, it could be seen that the biocathode achieved maturity.

CVs are extensively used to evaluate the bioelectrocatalytic activity of anode biofilms in MFCs [24, 25]. High current response represents more biological activity [26]. In this study, CVs were used to characterize the growth process of the cathode biofilm (Fig. 1b). As shown in Fig. 1b, the biocathode did not exhibit a significant current response in the first cycle because no microbes adhered to the carbon paper in this cycle. The current response in the third cycle was significantly higher than that in the first cycle. The increase in the current response could be attributed to the adhesion of some electroactive microbes on the carbon paper, and this adhesion improved the catalytic activity of the cathode. In the fifth cycle, the electroactive microbes adhering to the cathode increased further, and the catalytic activity of the cathode consequently was improved. In addition, the electroactive microbes completely adapted to the environment in this cycle. Thus, the current response further increased. At the end of the sixth cycle, a small sample of carbon paper was cut out from the biocathode and analyzed by SEM (Fig. 2). The SEM image shows that a biofilm layer was formed on the surface of the carbon paper. As reported by Chen et al. [27] and Pau et al. [28], most of the bacteria that attached to the cathode were rod-shaped.

Unlike previous start-up modes [13, 14], the "directstarting" procedure was used in this study. It only took $163 \mathrm{~h}$ for a successful start-up, and a current density of 

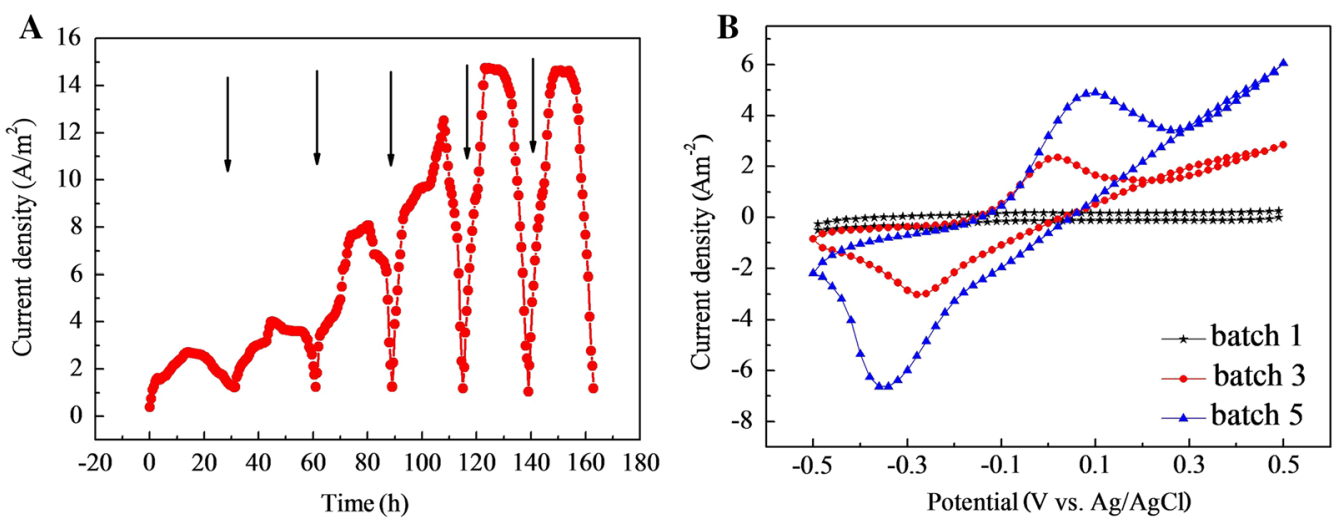

Fig. 1 Development of the current density of biocathode MEC at an applied voltage of $0.7 \mathrm{~V}$ (a), CVs of biocathode for the first, third and fifth cycles (b). (The arrows in Fig. 1a represented the replacement of nutrient solution.)

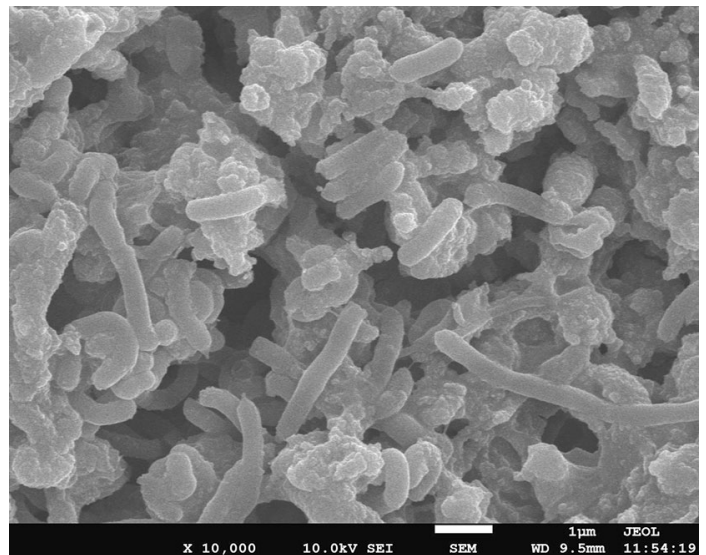

Fig. 2 SEM image of biocathode

$14.75 \mathrm{~A} / \mathrm{m}^{2}$ was obtained. This result showed that an $\mathrm{H}_{2}-$ producing biocathode community can develop directly from the inoculum, without having to convert the electrode from a bioanode.

\subsection{Performance of the Biocathode MEC in the Formal Hydrogen-Production Stage}

After start-up, the currents of the biocathode MEC were recorded during the four cycles and compared with those of the Pt/C cathode MEC (Fig. 3). As is shown in Fig. 3, the average current density of the biocathode MEC in the formal hydrogen-production stage was $9.752 \mathrm{~A} / \mathrm{m}^{2}$, which was slightly lower than that of the Pt/C cathode MEC $\left(9.931 \mathrm{~A} / \mathrm{m}^{2}\right)$. The peak current density of the biocathode MEC gradually increased in the formal hydrogen-production stage, which indicated the good stability of the biocathode. In the first cycle, the peak current density of the biocathode MEC was $13.775 \mathrm{~A} / \mathrm{m}^{2}$, which was $8.0 \%$ lower than that of the $\mathrm{Pt} / \mathrm{C}$ cathode MEC $\left(14.975 \mathrm{~A} / \mathrm{m}^{2}\right)$. However, in the second cycle, the peak current densities of the two MECs were both $15.3 \mathrm{~A} / \mathrm{m}^{2}$, which was higher than

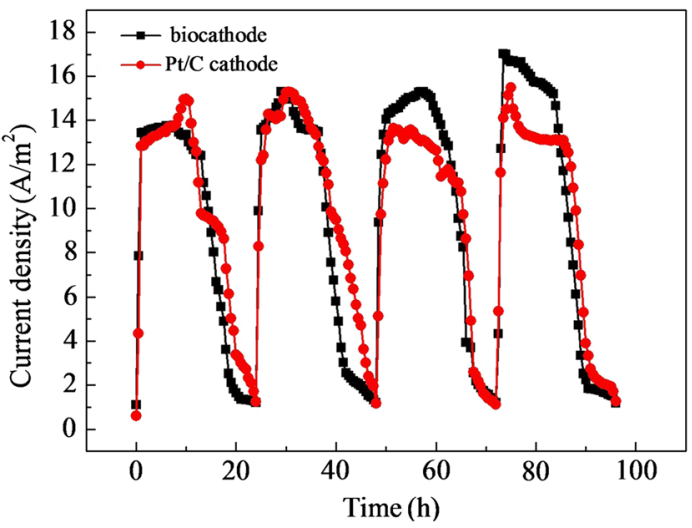

Fig. 3 Current generation for the biocathode and Pt/C cathode MEC at an applied voltage of $0.7 \mathrm{~V}$

their respective peak current densities in the first cycle. In the third and fourth cycles, the peak current densities of the biocathode MEC were 15.3 and $17.025 \mathrm{~A} / \mathrm{m}^{2}$, which were $12.7 \%$ and $9.8 \%$ higher than those of the $\mathrm{Pt} / \mathrm{C}$ cathode MEC, respectively. This result indicated that the biocathode was more durable than the $\mathrm{Pt} / \mathrm{C}$ cathode.

The hydrogen production of the two cathodes was measured, and the gas composition was analyzed by gas chromatograph (Thermo Fisher Scientific, Waltham, MA, USA). The coulombic efficiency $\left(R_{\mathrm{CE}}\right)$, electrical energy efficiency $\left(\eta_{\mathrm{W}}\right)$, hydrogen recovery $\left(R_{\mathrm{H} 2}\right)$, cathodic hydrogen recovery $\left(R_{\text {cat }}\right)$, and hydrogen production rate $(Q)$ were calculated. All the results are summarized in Table 1.

At an applied voltage of $0.7 \mathrm{~V}$, the $R_{\mathrm{CE}}$ and $\eta_{\mathrm{W}}$ of the biocathode MEC $(88.92 \pm 5.05 \%$ and $225.1 \pm 24.2 \%)$ were slightly lower than those of the Pt/C cathode MEC $(90.83 \pm 4.13 \%$ and $230.9 \pm 21.5 \%)$. However, the $R_{\mathrm{H} 2}$ and $R_{\text {cat }}$ of the former $(71.22 \pm 8.98 \%$ and $79.42 \pm 5.94 \%)$ were higher than those of the latter $(62.75 \pm 8.67 \%$ and $68.79 \pm 6.42 \%)$. The hydrogen production rate $(Q)$ obtained in the biocathode MEC 


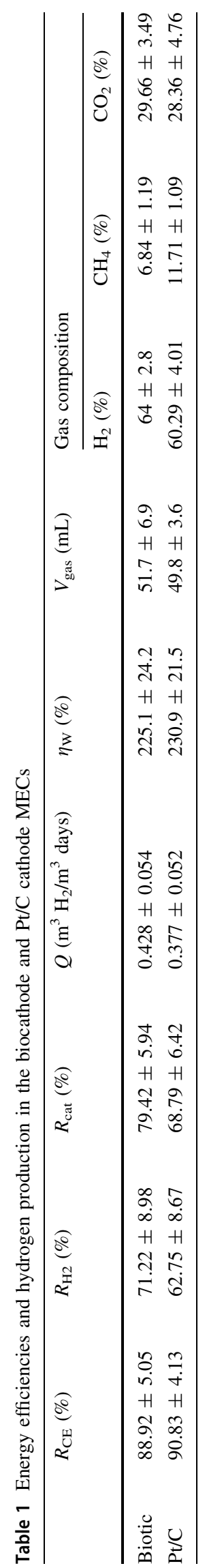

$\left(0.428 \pm 0.054 \mathrm{~m}^{3} \mathrm{H}_{2} / \mathrm{m}^{3} \mathrm{~d}\right)$ was slightly higher than that obtained in the Pt/C cathode MEC $\left(0.377 \pm 0.052 \mathrm{~m}^{3} \mathrm{H}_{2} /\right.$ $\left.\mathrm{m}^{3} \mathrm{~d}\right)$. The $\mathrm{H}_{2}$ content of the biocathode MEC $(64 \pm 2.8 \%)$ was higher than that of the $\mathrm{Pt} / \mathrm{C}$ cathode $\mathrm{MEC}$ $(60.29 \pm 4.01 \%)$, but the $\mathrm{CH}_{4}$ content of the former was lower than that of the latter. These results indicated that the biocathode possessed good catalytic activity for hydrogen evolution reaction.

\subsection{Bacterial Taxonomic Identification by $16 \mathrm{~S}$ Amplicon Sequencing}

Examining the microbial community structures of the inoculated sludge, biofilms of MFC and MEC are quite necessary to understand the complex interactions occurring between the microorganisms. In this study, 16S amplicon sequencing was employed to analyze the microbial communities in the original aerobic activated sludge (AAS), anodophilic biofilm of the MFC (MFC), anodophilic biofilm of the MEC (MECan), and cathodophilic biofilm of the MEC (MECca). After removing some low-quality sequences (those without an exact match to the forward primer, without a recognizable reverse primer, with some ambiguous base calls or length of which were shorter than $50 \mathrm{bp}$ ), over 38,000 high-quality sequences (i.e., 42,402, 43,773, 40,797, and 38,992 for AAS, MFC, MECan, and MECca, respectively) were obtained from each sample, and the median lengths were $420.38,417.40,416.18$ and $414.34 \mathrm{bps}$ for four samples, respectively. At a $3 \%$ distance, 4256 (AAS), 4089 (MFC), 3227 (MECan), and 3501 (MECca) operational taxonomic units (OTUs) were obtained. The total number of observed OTUs in the four communities was 11,615 , but only 471 OTUs $(4.06 \%$ of the total OTUs) were shared by them (Fig. 4). This result indicated that the environment had a significant influence on the microbial species. The majority of the shared OTUs was Proteobacteria (40.13\%), and $83.4 \%$ of the observed OTUs were unique to each community. New bacterial phylotypes continued to emerge even after 38,000 reads (Fig. 5). Therefore, $16 \mathrm{~S}$ amplicon sequencing can reveal a higher diversity of microbial communities than Sanger sequencing [29]. AAS presented the highest Shannon index (6.42) among the four communities. This result indicated the higher diversity of AAS than those of the communities. The Shannon indices of MFC, MECca, and MECan were $6.18,5.52$, and 5.24, respectively.

Hierarchical cluster analysis was performed to identify the similarities and differences among the four bacterial community structures (Fig. 6a). Two clusters, with MECca and MECan for one and AAS and MFC for another, were formed. The community structures of MECan/MECca and AAS/MFC were clearly distinct. These results showed that the applied voltage had an obvious effect on the 

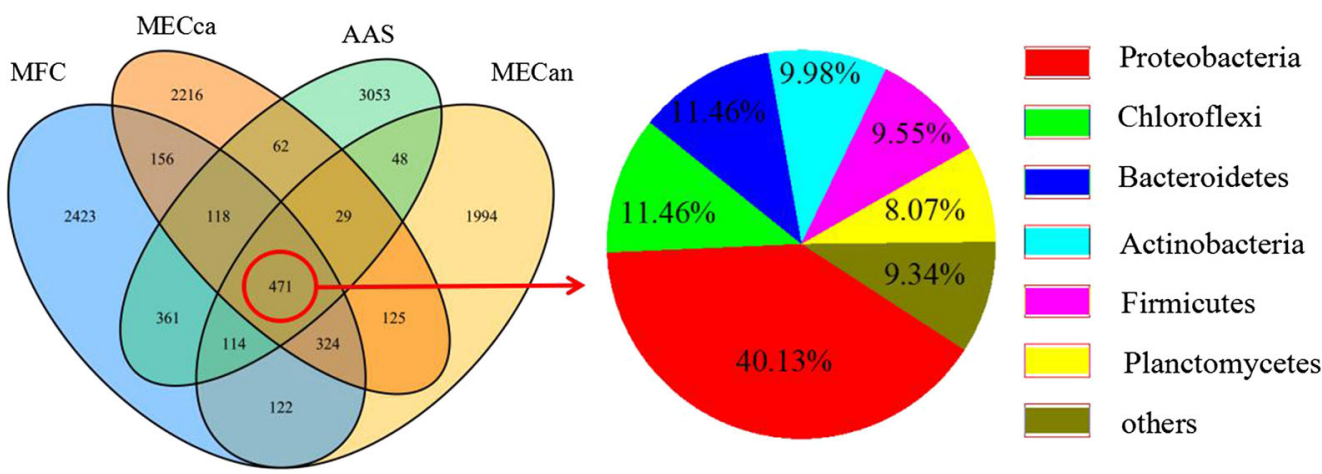

Fig. 4 Venn diagram of OTUs distribution from AAS, MFC, MECca and MECan (at 3\% distance thresholds), and the shared OTUs were analyzed at phylum levels

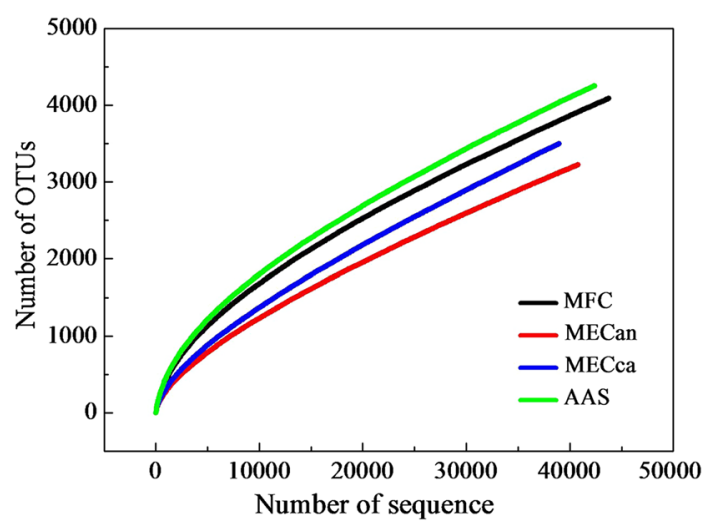

Fig. 5 Rarefaction curves of MFC, MECan, MECca and AAS microbial communities (at $3 \%$ distance)

community structures. Proteobacteria was evidently dominant in all communities, accounting for $59.73 \%$, $53.14 \%, 42.67 \%$, and $40.29 \%$ in MECan, MECca, AAS, and MFC, respectively. The distributions of the phyla Proteobacteria, Bacteroidetes, and Firmicutes in the total community composition represented the clearest differences among the four communities. The sums of the three phyla accounted for $85.13 \%$ (MECan), $78.52 \%$ (MECca), $72.45 \%$ (MFC), and $72.14 \%$ (AAS) of the total reads. Similar to the study of Lu et al. [30], the relative abundance of Firmicutes was lower in AAS (4.28\%) but higher in MECan (10.63\%), MECca (10.86\%), and MFC (13.39\%). Firmicutes is a major component of MFCs [31], and it is enriched with glucose and propionate feeding. Firmicutes was also enriched with acetate feeding in this study. The capability of Firmicutes to transfer electrons might be the reason for the selective enrichment on the biofilms [30]. By contrast, Bacteroidetes was higher in AAS $(25.19 \%)$ but lower in MECan (14.77\%), MECca (14.52\%), and MFC (18.77\%), which were different from those of Lu et al. [30].

The genus-level identifications of the bacterial communities in AAS, MFC, MECan, and MECca are illustrated in Fig. 6b. A total of 524 genera were classified from the four samples, and the relative abundance levels of the 14 genera exceeded $2 \%$. A total of 335 genera presented very low relative abundance levels $(<0.1 \%)$. The dominant population in MECan and MECca was the exoelectrogenic bacterial genus Pseudomonas (10.99\% and $6.74 \%$ of the total, respectively). Petrimonas, a fermentative acidogenic bacterial genus, also accounted for a large proportion, $4.03 \%$ in MECan and $3.24 \%$ in MECca. Geobacter, a widely known exoelectrogenic bacterial genus [30], was not detected in AAS but enriched in the other samples, particularly in MFC and MECan $(2.85 \%$ and $4.31 \%$, respectively). These results indicated that the microbial species changed in special growing environments. A special genus named Azospirillum was also not detected in AAS but enriched in MECan (4.59\%) and MECca (4.22\%), and only $0.97 \%$ in MFC. The applied electric field of MEC could be suitable for the growth of Azospirillum, and this species might be capable of producing hydrogen. Haliscomenobacter, a typical floc-forming bacteria in activated sludge accounted for low proportions in MECan $(0.06 \%)$ and MECca $(0.05 \%)$. Numerous unclassified bacteria with electricity- and hydrogen-production capabilities are not yet known. However, they could have contributed to the generation of electricity and hydrogen in the MEC.

\section{Conclusion}

Using a "direct-starting" procedure, the biocathode MEC was rapidly started up within $163 \mathrm{~h}$. The biocathode MEC performed better than the $\mathrm{Pt} / \mathrm{C}$ cathode MEC in hydrogen production, and the biocathode MEC was comparable with the latter in terms of current density and energy efficiency. The results of $16 \mathrm{~S}$ amplicon sequencing demonstrated that the microbial populations in MECan and MECca were less diverse than those in AAS and MFC. The applied electric field remarkably altered the microbial community structures between MECan/MECca and AAS/MFC. However, 
A Similarity

Taxonomic composition

Taxon

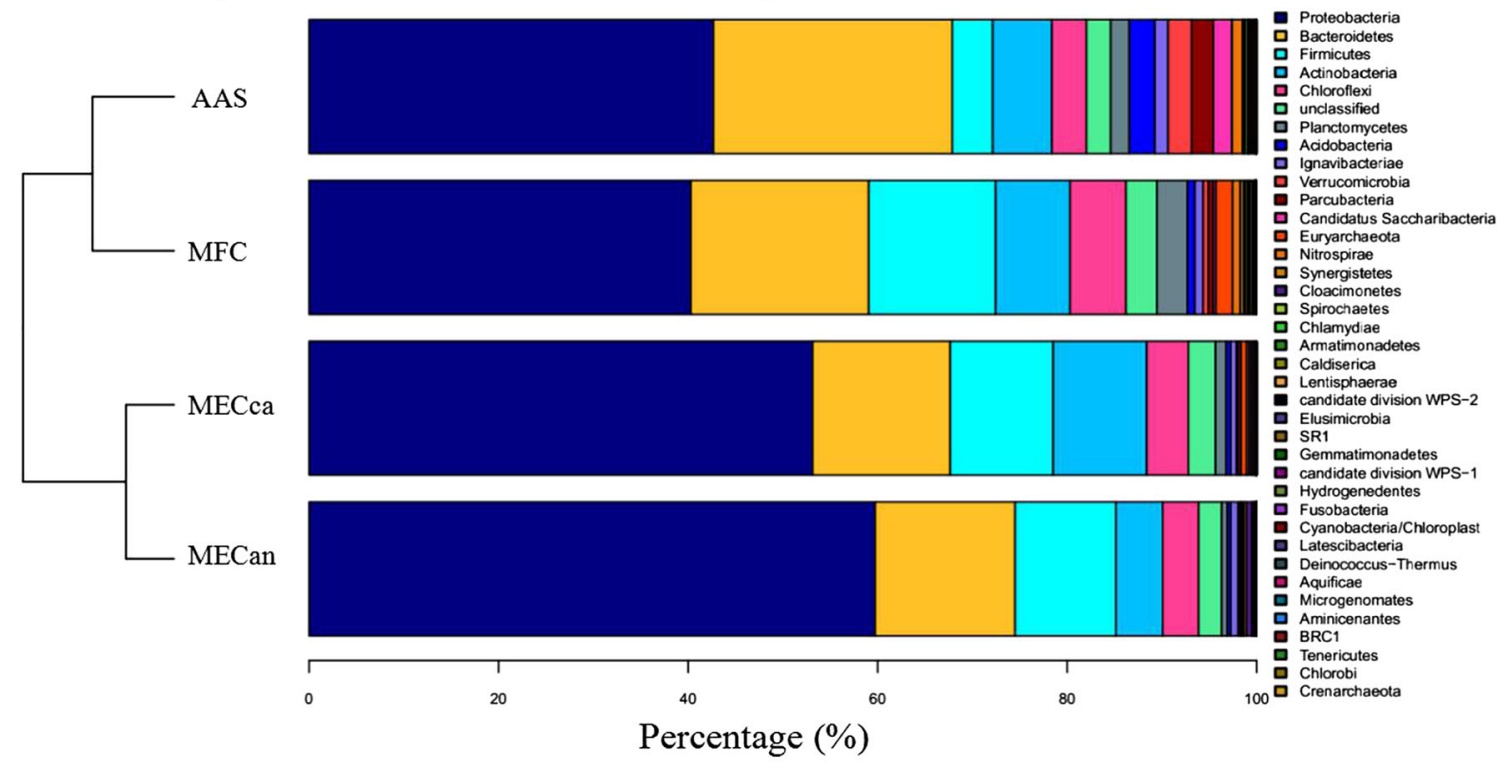

B

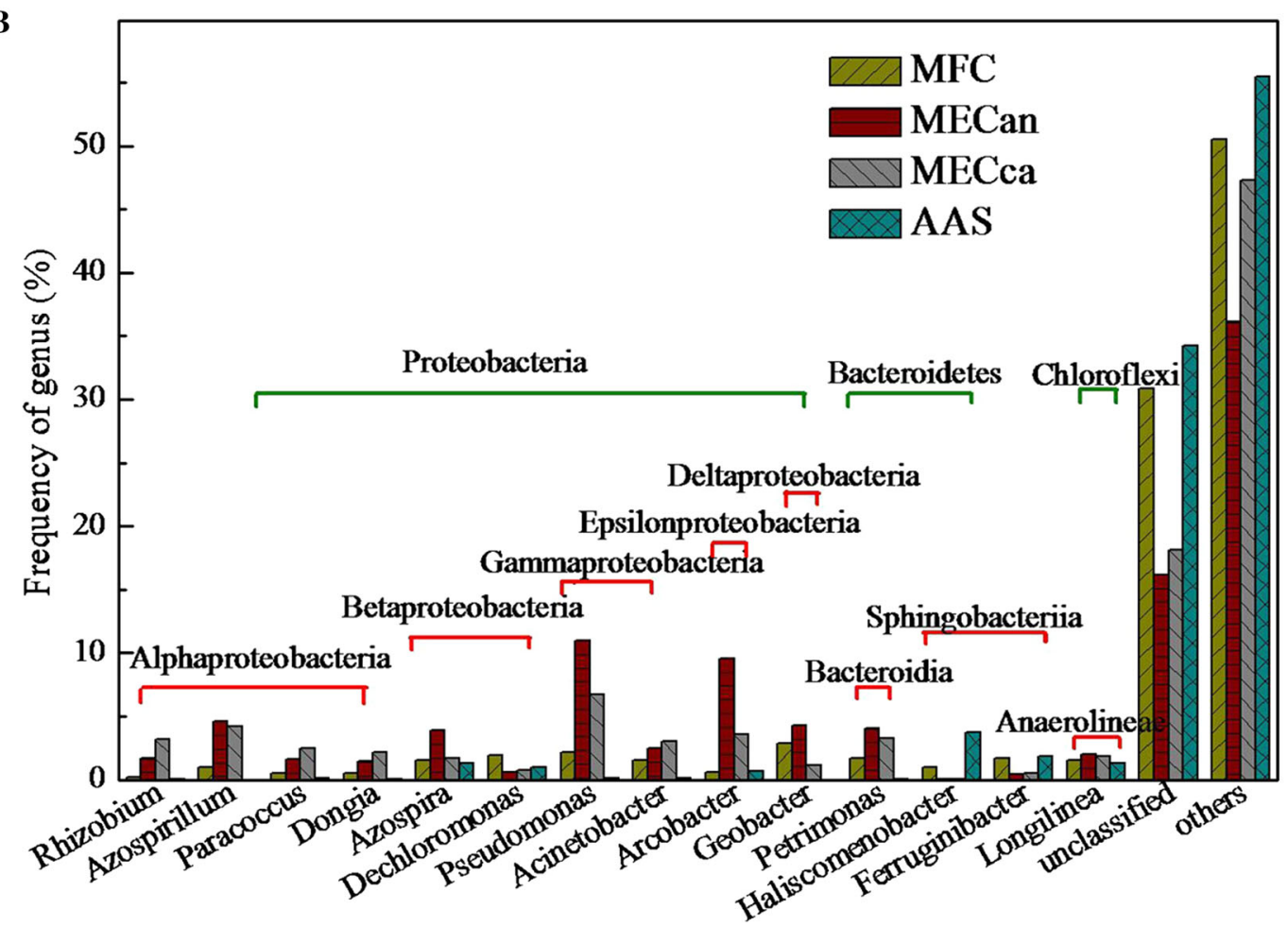

Fig. 6 Analysis of AAS, MFC, MECca and MECan bacterial communities: a hierarchical cluster analysis based on phylum level; b taxonomic classification of pyrosequences based on genus level

the genus Proteobacteria was dominant across all groups. This study provided a simple and feasible strategy for rapidly enriching for electroactive biofilms and presented the promising prospect of this strategy.

Acknowledgements This work is jointly funded by the National Natural Science Foundation of China (Grant No. 51703151) and the
Natural Science Foundation of Shanxi Province of China (Grant No. 201601D011023). 


\section{References}

[1] L.L. Wang, M. Al-Mamun, P.R. Liu, Y.L. Zhong, Y. Wang, H.G. Yang, H.J. Zhao, Acta Metall. Sin. (Engl. Lett.) 31, 431 (2018)

[2] Y.K. Kim, H.J. Seo, S. Kim, S.H. Hwang, H. Park, S.K. Lim, J. Mater. Sci. Technol. 32(10), 1059 (2016)

[3] H. Liu, S. Grot, B.E. Logan, Environ. Sci. Technol. 39, 4317 (2005)

[4] B.E. Logan, D. Call, S. Cheng, H.V.M. Hamelers, T.H.J.A. Sleutels, A.W. Jeremiasse, R.A. Rozendal, Environ. Sci. Technol. 42, 8630 (2008)

[5] Y.M. Zhang, M.D. Merrill, B.E. Logan, Int. J. Hydrog. Energy 35, 12020 (2010)

[6] M. Su, L.L. Wei, Z.Z. Qiu, G. Wang, J.Q. Shen, J. Power Sour 301, 29 (2016)

[7] L. Lu, D.X. Hou, Y.F. Fang, Y.P. Huang, Z.Y.J. Ren, Electrochim. Acta 206, 381 (2016)

[8] M.F. Manuel, V. Neburchilov, H. Wang, S.R. Guiot, B. Tartakovsky, J. Power Sour 195, 5514 (2010)

[9] J.C. Tokash, B.E. Logan, Int. J. Hydrog. Energy 36, 9439 (2011)

[10] F. Harnisch, G. Sievers, U. Schroder, Appl. Catal. B 89, 455 (2009)

[11] L. Xiao, Z.H. Wen, S.Q. Ci, J.H. Chen, Z. He, Nano Energy 6, 1 (2012)

[12] H.Y. Dai, H.M. Yang, X. Liu, X. Jian, Z.H. Liang, Fuel 174, 251 (2016)

[13] R.A. Rozendal, A.W. Jeremiasse, H.V.M. Hamelers, C.J.N. Buisman, Environ. Sci. Technol. 42, 629 (2008)

[14] A.W. Jeremiasse, H.V.M. Hamelers, C.J.N. Buisman, Bioelectrochemistry $\mathbf{7 8}, 39$ (2010)
[15] Q. Fu, H. Kobayashi, Y. Kuramochi, J. Xu, T. Wakayama, H. Maeda, K. Sato, Int. J. Hydrog. Energy 38, 15638 (2013)

[16] D.S. Horner, B. Heil, T. Happe, T.M. Embley, Trends Biochem. Sci. 27, 148 (2002)

[17] E. Croese, M.A. Pereira, G.J.W. Euverink, A.J.M. Stams, J.S. Geelhoed, Appl. Microbiol. Biotechnol. 92, 1083 (2011)

[18] A.J. Wang, H.Y. Cheng, B. Liang, N.Q. Ren, D. Cui, N. Lin, B.H. Kim, K. Rabaey, Environ. Sci. Technol. 45, 10186 (2011)

[19] E. Croese, A.W. Jeremiasse, I.P.G. Marshall, A.M. Spormann, G.J.W. Euverink, J.S. Geelhoed, A.J.M. Stams, C.M. Plugge, Enzyme Microb. Technol. 61, 67 (2014)

[20] J.S. Deutzmann, M. Sahin, A.M. Spormann, mBio 6, 496 (2015)

[21] H.Y. Dai, Dissertation (Taiyuan University of Technology, Taiyuan, 2017)

[22] D. Call, B.E. Logan, Environ. Sci. Technol. 42, 3401 (2008)

[23] H.Y. Dai, H.M. Yang, X. Liu, X. Jian, Z.H. Liang, Acta Metall. Sin. (Engl. Lett.) 29, 483 (2016)

[24] Y. Yuan, B. Zhao, S.G. Zhou, S.K. Zhong, L. Zhuang, Bioresour. Technol. 102, 6887 (2011)

[25] K.P. Katuri, P. Kavanagh, S. Rengaraj, D. Leech, Chem. Commun. 46, 4758 (2010)

[26] D.W. Liang, S.K. Pen, S.F. Lu, Y.Y. Liu, F. Lan, Y. Xiang, Bioresour. Technol. 102, 10881 (2011)

[27] Y.W. Chen, Y. Xu, L.L. Chen, P.W. Li, S.M. Zhu, S.B. Shen, Energy 88, 377 (2015)

[28] B.V. Pau, P. Sebastia, G.O. Rafael, V.P. Anna, B. Lluis, B.M. Dolors, C. Jesus, Int. J. Hydrog. Energy 39, 1297 (2014)

[29] S.A. Patil, V.P. Surakasi, S. Koul, S. Ijmulwar, A. Vivek, Y.S. Shouche, B.P. Kapadnis, Bioresour. Technol. 100, 5132 (2009)

[30] L. Lu, D.F. Xing, N.Q. Ren, Water Res. 46, 2425 (2012)

[31] X.C. Quan, Y.P. Quan, K. Tao, Chem. Eng. J. 210, 150 (2012) 